\title{
How to make urban freight transport by tram successful?
}

\author{
Katrien De Langhe ${ }^{*} \mathbb{D}$, Hilde Meersman, Christa Sys, Eddy Van de Voorde and Thierry Vanelslander
}

\author{
* Correspondence: katrien. \\ delanghe@uantwerpen.be \\ Department of Transport and \\ Regional Economics, University of \\ Antwerp, Prinsstraat 13, 2000 \\ Antwerp, Belgium
}

\begin{abstract}
Many national and international bodies, such as the European Commission, encourage the use of environment-friendly transport modes. Local and national authorities take more and more measures, for instance road pricing, loading/ unloading spaces and low-emission zones, to prevent negative transport-related externalities in urban areas. Hence, transport and logistics operators consider alternative ways to deliver goods in urban areas by using electric vehicles, cargo bikes, inland vessels and rail transport. Which of these alternative modes is appropriate for which transport flow depends on multiple factors, including the available transport infrastructure, the goods volume, the measures taken by the authorities and the presence of congestion. This paper focuses on urban freight transport by tram and the conditions for a successful implementation. A successful implementation is defined as an implementation that is viable, i.e. the difference between the change of the costs and the change of the benefits exceeds a certain threshold value. The viability is studied from a business-economic and a socioeconomic perspective for a dedicated freight tram, a freight wagon behind a passenger tram and the transport of parcels by a passenger tram. A viability model is developed, based on a social cost-benefit analysis. The working of this model is illustrated by applying it to the city of Antwerp. The main findings show that the use of a freight wagon attached to a passenger tram provides more potential than a dedicated freight tram. A courier taking the tram to deliver some parcels can be viable as well. For all three types of tram transport, the socio-economic benefits exceed the business-economic ones. Critical factors affecting the viability include the transported volume, the efficiency of the current road transport, the timing of the transport, the need for post-haulage and the operational costs of both road and rail.

Keywords: City logistics, Urban freight distribution, Rail, Tram, Social cost-benefit analysis
\end{abstract}

\section{Introduction}

Many national and international bodies, such as the European Commission (2018) and the United Nations (2018), encourage the use of environment-friendly transport modes. At local and national level, more and more measures are taken by authorities (Letnik et al. 2018), for instance road pricing, loading/unloading spaces and lowemission zones, to prevent negative transport-related externalities in urban areas (Cavallaro et al. 2018; Chang et al. 2018; Maes et al. 2011). These measures make delivering goods in urban areas by road vehicles more challenging, since it often becomes

(c) The Author(s). 2019 Open Access This article is distributed under the terms of the Creative Commons Attribution 4.0 International License (http://creativecommons.org/licenses/by/4.0/), which permits unrestricted use, distribution, and reproduction in any medium, provided you give appropriate credit to the original author(s) and the source, provide a link to the Creative Commons license, and indicate if changes were made. 
more expensive and requires changes in the business models of transport operators (Cruz and Montenon 2016).

Hence, transport and logistics operators consider alternative ways to deliver goods in urban areas by using electric vehicles, cargo bikes, inland vessels and rail transport (Diziain et al. 2014; Maes 2017; Mirhedayatian and Yan 2018; Trojanowski and Iwan 2014). In this context, one of the themes in the city logistics literature investigates the use of rail for urban freight distribution instead of traditional road transport. When using rail to transport urban freight, either available rail infrastructure in the urban area can be used, new infrastructure can be constructed, or both the existing and new infrastructure can be utilised.

Pimentel and Alvelos (2018) find that the combination of passenger and freight flows is almost inexistent in the last-mile literature and thus, it is an interesting topic to examine. Many urban areas possess rail infrastructure, which is often not used at full capacity, but seldom is this infrastructure used for freight activities. Using the passenger infrastructure to transport goods is one way to reduce the current urban road traffic (Behiri et al. 2018) and hence, to reduce environmental effects to society. Moreover, Macario et al. (2011) and Bektas et al. (2016) see some attractive business opportunities by combining the transport of passengers and freight in the same vehicles, leading to economies of scope, including lower rolling stock and personnel costs. As passenger demand varies during the day, the spare capacity of the urban passenger transport network in off-peak moments could be used to transport freight (Pimentel and Alvelos 2018). Given the gap in the literature and the insufficiently studied business-economic and environmental opportunities, the objective of this paper is to investigate the use of rail for urban freight transport and the conditions for a successful implementation. A successful implementation means that the use of a rail-based scheme is viable from a business-economic and a socio-economic viewpoint (Sartori et al. 2015). ${ }^{1}$ From a business-economic perspective, the rail-based scheme is viable if the change of private benefits minus the change of private costs exceeds a certain private threshold value. From a socio-economic viewpoint, the scheme is viable if the difference of the change of the social benefits minus the change of the social costs exceeds a certain socioeconomic threshold value. The analysis is done from the perspective of the infrastructure owner, in this case the authorities. Indirect effects, such as employment effects, are not included in the analysis (Aronietis et al. 2016).

In general, rail comprises heavy rail, light rail, trams and metros (Kikuta et al. 2012; Motraghi and Marinov 2012). This paper focuses on the use of trams. Trams were often used to transport goods (Annys et al. 1994; Van Heesvelde et al. 2018) until the car and truck became more popular in the course of the twentieth century thanks to their flexibility. Given the increasing congestion and air quality issues, it is most interesting to examine whether the use of trams for urban freight transport could provide a solution. Cochrane et al. (2017) highlight the need for an economic analysis of railbased urban freight strategies. These authors state that an urban rail-based scheme should be modelled in order to estimate the operational and environmental effects. Therefore, in the current paper, a novel viability model is developed based on a cost-

\footnotetext{
${ }^{11}$ Sartori et al. (2015) use the terminology "financial analysis - return on investment" for what is considered here as the business-economic analysis and the terminology "economic analysis" for what is considered here as the socio-economic analysis.
} 
benefit analysis. This model allows calculating the business-economic and socialenvironmental costs and benefits that emerge when goods are transported by tram instead of by truck or van. Moreover, the model makes it possible to measure the effect of a change of one or more variables characterising the tram initiative on the costs and the benefits by providing sensitivity analyses. As an illustration of the viability model, the decision is made to show calculation results for the city of Antwerp (Belgium).

This paper extends the vast body of literature on city logistics and on combined passenger and freight flows in two ways. Firstly, the key strength of the paper is the novel methodological framework that is offered and that can be applied to other urban areas. The model allows understanding how one feature of for instance the urban area or the tram infrastructure can alter the success potential of using a tram for freight purposes. Moreover, in the newly developed model freight can be loaded on the tram at multiple points and multiple deliveries can be made. This is new compared to most existing studies treating freight transport by tram, in which a point-to-point route is considered. Secondly, the paper adds knowledge on the possibilities of using available tram infrastructure for freight purposes in Belgium. Furthermore, the paper can help demonstrating for instance public transport operators the added value of applying cost-benefit analyses when making decisions with respect to infrastructure and operations. Vigren and Ljungberg (2018) show that public transport authorities seldom use cost-benefit analyses, whereas literature states that this method is very appropriate to support such decisions (Blauwens et al. 2016; Gonzalez-Feliu 2016).

The rest of this paper proceeds as follows. The next section provides a synopsis of the urban rail freight literature. The following section presents the viability model. Subsequently, the data used in the model application are clarified. The following section shows the results of the application of the viability model for the city of Antwerp. Ultimately, some conclusions are drawn and further research is proposed.

\section{Urban freight transport using the public transport network}

Considering a tram, goods can be transported using a dedicated freight vehicle, in a freight wagon behind a passenger tram, or a small amount of parcels can be transported in a passenger tram. These three types of transport differ amongst others concerning the volume that can be transported and the capital investment needed. Hence, the literature review in the following subsections is split into these three types of tram transport.

\section{Dedicated freight vehicle}

The most examined way of transporting goods by tram is by using a dedicated freight tram. These trams were used until the beginning of the twentieth century to transport various types of goods. Around 1950, these trams were taken out of operation due to the increasing popularity of the car (Annys et al. 1994; Van Heesvelde et al. 2018). Some examples of more recent dedicated freight trams are the CarGo Tram of Volkswagen in Dresden, and the Cargo-Tram and E-Tram in Zurich (Arvidsson and Browne 2013; Cleophas et al. 2018; Marinov et al. 2013). Other pilot projects that have been taken place are amongst others City Cargo in Amsterdam (Motraghi and Marinov 
2012), GüterBim in Vienna, TramFret in Paris and Saint-Etienne (Cleophas et al. 2018) and Logistiktram in Frankfurt (VGF 2018).

In the academic literature, several authors pay attention to the possibility of using a dedicated freight tram. Arvidsson (2010) suggests to use old passenger tram vehicles to transport freight. Arvidsson and Browne (2013) examine the success of the City Cargo freight tram project in Amsterdam. Regué and Bristow (2013) investigate the use of the tram infrastructure in Barcelona for the transport of retail products and waste and conduct a cost-benefit analysis. Gonzalez-Feliu (2016) examines the costs and benefits of the TramFret project in France. Ozturk and Patrick (2018) also describe the latter project, confirming that for this case study too, recycled passenger trams are used. Cochrane et al. (2017) analyse different freight on-transit strategies, including the transport of packages between the airport and the central station in the Greater Toronto and Hamilton area by dedicated freight trains, and supplying retailers in a large shopping centre by a dedicated metro. Cleophas et al. (2018) describe the CargoTram and E-Tram in Zurich, which is a dedicated freight tram using the available public tram infrastructure. The GüterBim in Vienna is another case study discussed by these authors, where a dedicated freight unit also used the available passenger tram infrastructure. Some new tram sections had to be constructed in order to deliver the goods to some stores and restaurants in the city.

\section{Freight wagon behind a passenger vehicle}

Examples of vehicles transporting freight behind passenger trams are less occurring. In 1911, the so-called "suitcase tram" was used in Belgium. This was a closed freight wagon attached to a passenger wagon in which the suitcases of travellers were stored. During World War I, these freight wagons were used to transport other types of freight. Since 1961, the wagon is not operational anymore (Van Heesvelde et al. 2018, 110). Shen et al. (2015) explore the idea of transporting freight in trailers attached to a scheduled public passenger bus. In their proposed system, the trailers are automatically unloaded at a certain bus stop, while the passengers get on or off the bus. Cochrane et al. (2017) investigate the transport of drinks in a freight wagon attached to a tram during off-peak hours in the Great Toronto and Hamilton area. Behiri et al. (2018) propose to have some dedicated freight cars at the back of the train, which are inaccessible for passengers.

\section{Freight in a passenger vehicle}

The most known example of transporting freight in public transport vehicles is the transport of mail. Examples of mail transport by passenger buses or trams are especially found for the 19th and twentieth century, for example in Belgium and Germany (Annys et al. 1994; Cleophas et al. 2018; Fredriks.de 2018). Since 2007, Citipost has placed mail boxes in trams in Bremen, in which passengers can depose their mail (Posttip.de 2007). Kikuta et al. (2012) organised a pilot in which a hand cart was loaded on board of a passenger subway wagon in the Japanese city Sapporo. In more recent studies, both the use of a bus and a tram and train is examined. Cochrane et al. (2017) examine the transport of low-priority mail and packages in freight compartments in commuter trains. Pimentel and Alvelos (2018) propose a model in which the city bus network is 
used to transport parcels. The model is applied to buses following a fixed route. Hence, the system can be compared to an urban tram network, having as an intrinsic characteristic that the trams also have to follow a fixed route.

Which of these types of tram transport is appropriate for which transport flow depends on multiple factors, including amongst others the available transport infrastructure, the goods volume, the time of the transport, the measures taken by the authorities and the presence of congestion (Alejandro Cardenete and López-Cabaco 2018; Arencibia et al. 2015; Regué and Bristow 2013). Moreover, the type of goods transported also affects the suitableness of tram transport. A distinction between non-food products, frozen food, cooled food and non-cooled food can for instance be made (Ayadi 2014). Each product type has other characteristics, leading to other costs such as cooling, handling and depreciation. In order to determine how critical these factors are to successfully implement a tram for urban freight transport, a detailed cost-benefit analysis is necessary. Due to the complexity and the different environmental factors affecting the success potential, for instance the presence of congestion on the road network which affects the speed of the current transport by road, the need exists to develop a generic model that allows taking into account all kinds of complexity.

\section{Developing the viability model}

In order to investigate whether and how using a tram for urban freight distribution can be successful, a generic model is developed. A social cost-benefit analysis is used as the starting point. Figure 1 shows schematically how the viability model is constructed and how it works.

The viability model displayed in Fig. 1 consists of three main parts, being the input, the calculations and the output. Firstly, data concerning the reference and project scenario are used as input. Secondly, the appropriate module of the calculations part is activated. Currently, three modules are available in the model, being module 1.1: dedicated freight tram, module 1.2: freight wagon behind a passenger tram, module 1.3: freight in a passenger tram. The model leaves the possibility to add as many modules as wanted. Thirdly, the business-economic and socio-economic results of the

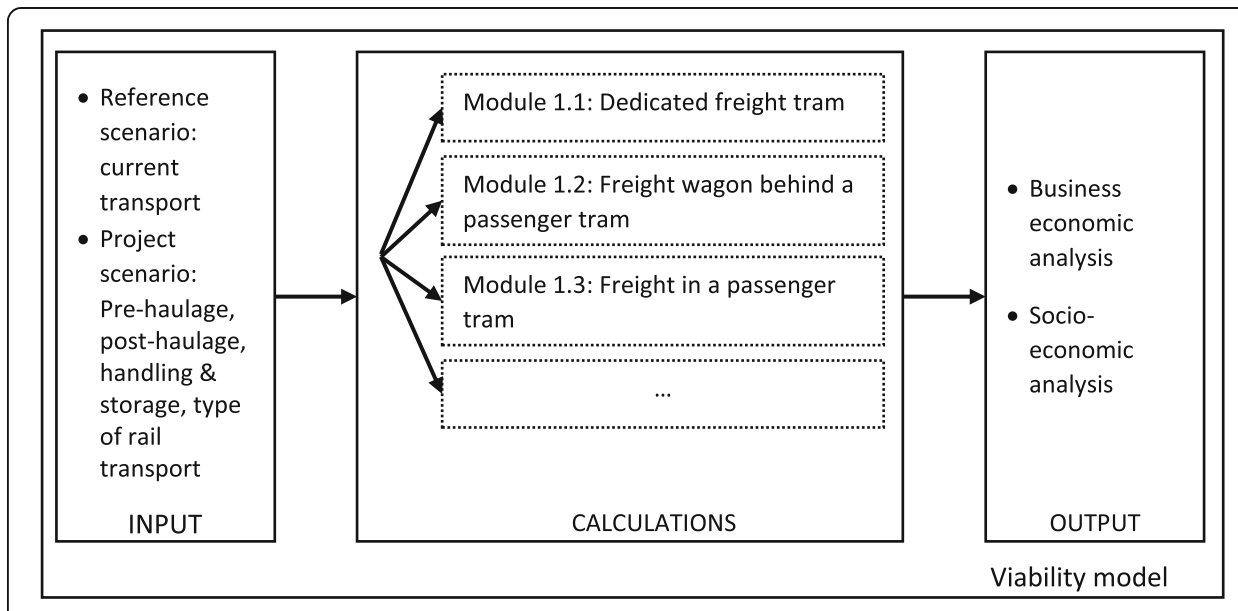

Fig. 1 Viability model for urban freight by tram 
calculations are available in the output. The following sections provide more detailed information on the different parts of the viability model.

\section{The input}

In the input part, data are collected with respect to the characteristics of the reference scenario and the project scenario. Based on a literature review and an expert meeting among industry and academic experts, the critical characteristics that have to be defined for the reference and project scenario are identified. The reference scenario is defined by the features of the current transport by road. The project scenario is characterised by all features of the urban rail freight supply chain. This chain consists of rail transport, potential road pre- and post-haulage, and potential additional handling and storage when shifting from road to rail.

Firstly, some characteristics of the current transport by road have to be specified. Examples of data needed here for every conducted round trip are the current distances covered to reach the customer in the urban area, the timing of the transport, being peak-hour, off-peak hour or during the night, the main product type that is transported, the value of the goods delivered at the customers and the location of the customers. A round trip is defined in this research as the transport of goods from one supplier to one or more customers in an urban area and the trip back to the supplier's premises. Additional information that is required for each round trip is the goods volume delivered at each customer and some vehicle characteristics such as the fuel type, the tonnage and the euro standard. Ultimately, the average speed of the road vehicles to fulfil the round trips has to be indicated.

Secondly, some decisions have to be made with respect to the handling and storage when the shift from road to tram is made. It has to be decided at which location at the edge of the city the goods are loaded on the tram, as well as at which point in the city centre the goods are unloaded from the tram. For both handling points, it has to be indicated whether the goods are only transferred (transit platform), or also stored for a while (distribution centre).

Thirdly, for each roundtrip, the distance that has to be covered between the supplier and the location at the edge of the city, where the goods are loaded on the tram, has to be clarified.

Fourthly, for each customer receiving goods, the nearest tram stop has to be chosen. Other information that is required is the distance that still has to be covered between the tram stop and the customer and the way the post-haulage transport (if needed) is done. Currently, six possible ways of post-haulage are available in the model: the tram stops in front of the customer, a shop employee walks to the tram stop and picks up the goods, a member of the tram personnel brings the goods to the customer, a traditional cargo bike service is used, an electric cargo bike service is used, or an LGV is used. In case of the use of an LGV, the euro standard of the LGV, as well as whether the LGV operates on petrol, diesel or electricity, has to be added. Moreover, if the goods are stored at the tram stop for a while, the timing of the post-haulage transport can be chosen.

Fifthly, some tram characteristics are specified. These features include the length of additional sidings to the existing tram network that have to be constructed, the type of 
tram vehicle, the way electricity is generated, the amount of advertisement space sold on the tram vehicle and whether the tram has its own right of way, or whether this is shared with road traffic. Moreover, the tram trips are specified in the sense that for each tram trip the handling and storage point at the edge of the city, and the tram stops in the city centre are indicated, as well as the timing of the tram trips.

\section{The calculations}

The calculations are executed for each module separately. Depending on the type of tram transport selected in the input part, another module is activated. Hence, the business-economic and social-environmental costs and benefits of using that particular type of tram transport are compared to the current transport by road. Four main components of costs and benefits are identified, being the private cost, private benefit and external cost and benefit. Other social-environmental costs and benefits that are not captured by the external costs and benefits, such as the public attractiveness of using trams, are in the current model not quantified. An in-depth demand analysis is needed in order to quantify these costs and benefits, and this is beyond the scope of the current paper. Given the small-scale illustration of the model here, it is assumed that omitting the public attractiveness of using trams for freight transport does not alter the main findings. The generalised cost approach is used for the analysis. This means that next to the time and distance costs and benefits, also the value of time is taken into consideration, which is related to the value of the goods transported. In particular, the latter is included in the analysis by examining the inventory carrying cost (Blauwens et al. 2016).

\section{Private cost}

The private cost of using rail instead of a truck or van consists mainly of the capital investment and the operational costs. Capital investment includes the potential investment in sidings, i.e. tracks and switches, rolling stock and handling and storage points, such as transit platforms or distribution centres. For the capital investment calculations, the life span of the infrastructure is taken into account, as well as the replacement costs and potential residual value. The need for capital investment varies a lot depending on the type of tram transport.

The operational costs comprise the costs of operating the tram, the track access charges to use the public tram network, the costs of operating the road pre- and/or post-haulage, potential road pricing in the road pre-haulage leg, and the costs of operating the transit platform and/or distribution centre where the goods are moved from truck to rail or vice versa. These operating costs consist of time and distance costs and include amongst others labour, electricity, fuel and insurance (Blauwens et al. 2016).

\section{Private benefit}

The private benefit consists of the revenue generated by the tram service operator and potential customers' benefits. The revenue of the tram service operator related to the freight transport is difficult to estimate, since the service currently does not exist. Therefore, it is assumed that the shipper does not want to pay more than what he is paying today for the transport by road. Potential customers benefits comprise saved 
shop surface, saved shop personnel, a reduced inventory carrying cost and advertisement revenue. In case the goods are delivered by tram in smaller and more frequent quantities, the customers in the urban area can use more space for sales purposes instead of storage purposes. However, if the goods are delivered by tram in larger and thus, less frequent quantities, this benefit becomes an additional cost for the customers, since more storage space is needed (Blauwens et al. 2016). Shop personnel can be saved if the delivery by tram occurs such that the shop personnel can work more efficiently. A reduced inventory carrying cost is obtained if there are time gains by transporting the goods by tram instead of by truck or van. Ultimately, some advertisement revenue is potentially present if advertisement space on the tram is sold to third parties.

\section{External cost and benefit}

The external cost includes all costs related to externalities caused by the tram, the road pre- and/or post-haulage and the handling and storage. External cost components considered are accidents, air pollution and climate change, congestion, infrastructure damage and noise (Korzhenevych et al. 2014). The external cost of potential up- and downstream processes, such as the generation of electricity, is included in the other cost components. The external benefit of using a tram instead of a truck or van is equal to the reduction of road external cost.

\section{The output}

The third part of the developed model shows the business-economic and socioeconomic results of the viability model. The business-economic analysis evaluates the consolidated project viability. The methodology used to calculate this viability is the discounted cash flow method. When the authorities are leading the investment, the needed equity is considered to be part of the national capital. Hence, no capital financing costs are considered to calculate the return on investment. However, if the capital owner is a private stakeholder, costs of financing by using own equity have to be taken into account by adding equity opportunity costs to the calculations. Moreover, an analysis can be made of the return on capital, by assuming that part of the capital investment comes from a bank loan. Following Sartori et al. (2015), a financial discount rate is used, which represents the opportunity cost of capital. In the remainder of this paper, the authorities' perspective is adopted, assuming that national capital is invested.

The socio-economic analysis appraises the contribution of the project to welfare. Some effects are not valued in the market and are therefore not included in the business-economic analysis. However, from a welfare perspective, they contribute to the costs and benefits related to the project. Thus, in the socio-economic analysis these effects are added by using shadow prices. A social discount rate is used in this analysis, which represents the social view on how costs and benefits should be compared to the present ones (Sartori et al. 2015).

For both analyses, the resulting net present value (NPV) and internal rate of return (IRR) are calculated in order to assess whether the project should be put in practice. Equation (1) shows that the NPV is calculated based on the net benefits for every year $t$ $\left(\mathrm{NB}_{\mathrm{t}}\right)$, and the annual discount rate i. A financial discount rate is used for the business- 
economic analysis, whereas a social discount rate is used for the socio-economic analysis. In this paper, a time horizon of 30 years is considered $(\mathrm{T}=30)$.

$$
N P V=\sum_{t=0}^{T} \frac{N B_{t}}{(1+i)^{t}}
$$

Moreover, it is suggested by several authors that sensitivity analyses have to be performed with respect to the effect of variables on the project outcome. Delaitre and De Barbeyrac (2012) conduct sensitivity analyses concerning the operational cost of rail transport. Regué and Bristow (2013) evaluate the effect of a change of the capital investment on the viability of using a freight tram in Barcelona. Comi et al. (2014) mention in general the importance of knowing the effect of the operational costs and marketing revenue on the rail-based viability. The operational costs of road transport depend amongst others on the speed and hence, the presence of congestion. Vadali et al. (2017) also declare the need to conduct sensitivity analyses with respect to the capital investment, operating costs, assumed travel times, freight values of time, the discount rate and the temporal scale of the analysis. Freight values of time can be captured by taking into account the discount rate of the goods. One important factor related to the temporal scale of the analysis is the inflation rate. Boardman et al. (2018) highlight the importance of checking the effect of the discount rate on the project outcome. All variables mentioned here are used in the sensitivity analyses conducted in the following section.

\section{Illustration of the viability model}

This section provides an illustration of the developed viability model. The aim of this illustration is to show how the developed model can be used in practice.

\section{Reference and project scenario}

The reference scenario is designed for a round trip by road transport in the situation illustrated in Fig. 2. All round trips in the rest of the paper, are considered to have the same characteristics. The supplier transports goods to three customers, located in an urban area. This transport is done by a rigid diesel van of $3.5 \mathrm{t}$ gross weight and a euro

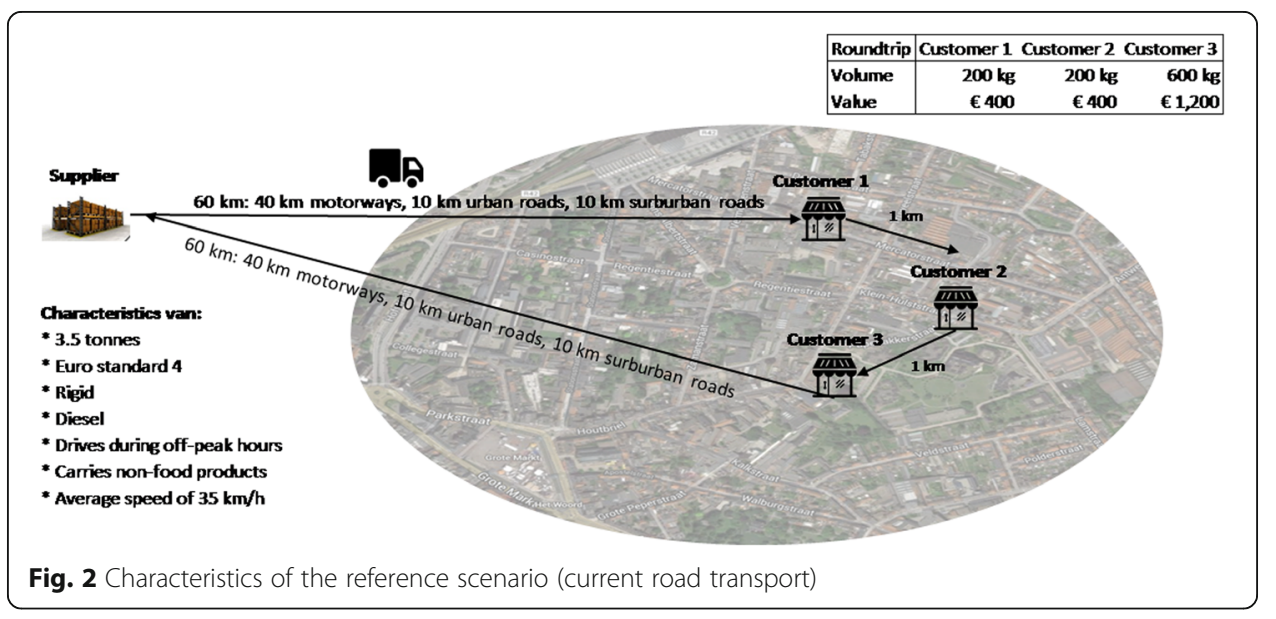


standard 4. The van operates during off-peak hours, carries non-food items and has an average speed of $35 \mathrm{~km} / \mathrm{h}$. The distance covered to reach the first customer, is set at 60 $\mathrm{km}$. In this total distance, the van drives $40 \mathrm{~km}$ on motorways, $10 \mathrm{~km}$ on urban roads and $10 \mathrm{~km}$ on suburban roads. If the van is $100 \%$ filled, customer 1 and customer 2 each receive $200 \mathrm{~kg}$ of goods, while customer 3 gets $600 \mathrm{~kg}$ of goods delivered. Furthermore, the average value of the goods is approached by 2 euro per kilogram. This approximation is altered in the sensitivity analyses.

The project scenario is developed for a round trip by tram transport complemented by road pre-haulage in the situation illustrated by Fig. 3. The vans of the current road transport are still used, but now only for the road pre-haulage until a certain handling and storage point at the edge of the city centre. The number of van trips needed depends on the van capacity and on the amount of goods to be transported. At the handling and storage point, the goods are loaded on a tram ${ }^{2}$ and the tram transports the goods towards a tram stop located in the neighbourhood of the customers. It is assumed here that no road post-haulage is needed. The tram uses $100 \%$ green electricity, drives during off-peak hours following Behiri et al. (2018) and shares it way with the road traffic, slightly reducing its average speed from $18 \mathrm{~km} / \mathrm{h}$ to $15 \mathrm{~km} / \mathrm{h}$.

For both scenarios, the financial discount rate is set at 4\% (Blauwens et al. 2016; Sartori et al. 2015) and the social discount rate at 4\% (Kidokoro 2004; Sartori et al. 2015). The time horizon is considered to be 30 years for urban rail projects (Sartori et al. 2015) and all values are expressed in real euros based on the consumer price index.

\section{The city of Antwerp as a study area}

The viability model is now illustrated for these round trips in the city of Antwerp, which is the second largest city of Belgium in terms of population. In January 2018, 524,501 people were living in Antwerp (City of Antwerp 2018). The city has an urban tram network, which is currently being extended. Antwerp suffers from congestion, with an average congestion level ${ }^{3}$ in 2016 of 30\%, an average morning peak level of $51 \%$ and an evening peak level of $62 \%$. As shown in Fig. 4, most of the delay hotspots are located on the main motorways leading to Antwerp and especially on the ring road

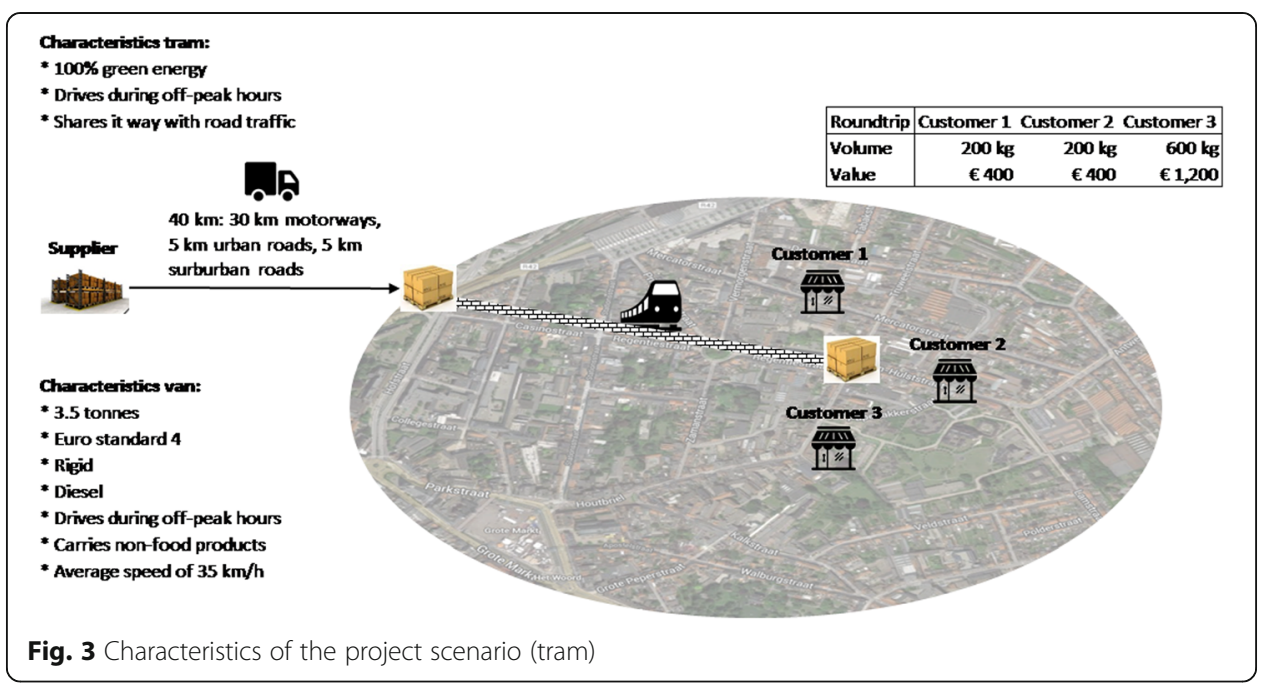




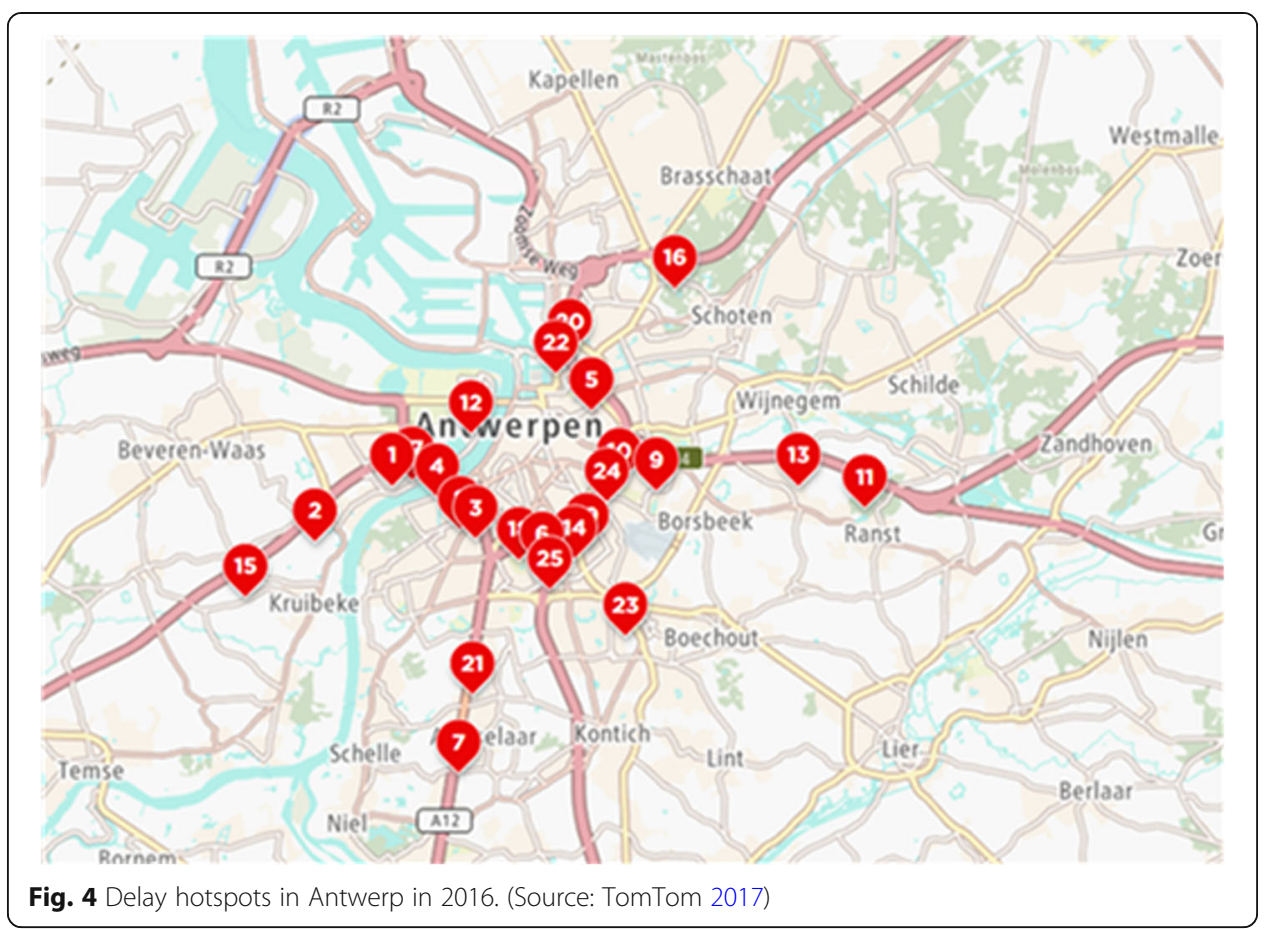

around Antwerp, which makes it challenging to enter the Antwerp urban area by road. Moreover, the city introduced a low emission zone in February 2017, covering the area enclosed by the ring road, as well as a part of the left bank of the river Scheldt (Slim naar Antwerpen 2019). Ultimately, in Belgium, trucks of more than $3.5 \mathrm{t}$ have to pay a road pricing fee when they drive on the motorways and on some main roads (Viapass 2018). The road pricing fee is included in the developed model, but the cost equals zero for the given reference and project case, since vans of $3.5 \mathrm{t}$ are used.

\section{Results}

The results of the viability model differ depending on the type of tram transport that is used. Therefore, the following sections discuss the results for each of the three tram types separately. It is assumed that the same non-food retail products are transported in the three modules in order to avoid bias when comparing between the modules. Hence, the products transported by the three tram types have the same total logistics unit cost (Ayadi 2014).

\section{Dedicated freight tram (module 1.1)}

The first illustration of the viability model concerns the use of a dedicated freight tram. Firstly, the model was run given the inputs and data described above. Secondly, the model was altered with respect to the transported volume. Following Campos and Hernández (2010) and Regué and Bristow (2013), the question rises which volume is

${ }^{2}$ Depending on the type of tram chosen, the goods will be transferred to a dedicated freight tram (module 1.1), a freight wagon attached to a passenger tram (module 1.2), or a courier takes the goods in the tram (module 1.3).

${ }^{3}$ The congestion level is the additional time needed to cover a certain distance compared to the free flow traffic. 
minimally required to have a viable tram-based solution. The transported volume in the current situation can be altered in four ways: by considering larger or smaller trucks, by considering higher or lower load factors of the existing vans, by adding additional round trips, or by adding new customers receiving goods in the urban area. In this research, it is chosen to keep the type of vehicle fixed to vehicles of $3.5 \mathrm{t}$ gross weight, as well as to keep the number of customers served in the urban area unchanged. Hence, the variables 'load factor' and 'number of round trips' are altered in order to see the effect of a volume change on the viability of the tram-schedule. It is assumed that a load factor of a van can be $50 \%, 60 \%, 70 \%, 80 \%, 90 \%$ or $100 \%$ and the number of round trips considered equals either three, four, five or six. The possible number of round trips is chosen such that the point at which the tram-based solution becomes viable, in terms of net present value and internal rate of return, is found to be in this range.

For all combinations of these number of round trips and load factors, the net present value and internal rate of return are calculated from a business-economic and socioeconomic perspective. The respective resulting net present values are displayed in Figs. 5 and 6. For each combination of a number of round trips and load factor, the net present value is shown. The interesting point, where the net present value becomes positive, is presented as the line between the black and grey shaded area on the business-economic graph (Fig. 5), whereas on the socio-economic graph all NPVs are positive (Fig. 6). In Figs. 5 and 6, the net present value decreases when the load factor of the truck increases. This corresponds to what could be expected, since a higher load factor of the truck means that the road transport is more efficient and hence, it makes less sense to shift to rail. Along the axis displaying the number of round trips, it can be seen that the net present value increases when the number of round trips increases. For the internal rate of return, a similar pattern exists.

The tram-based solution is only interesting to be put in practice if the businesseconomic and socio-economic net present value is positive, and the internal rate of return equals at least respectively the financial and social discount rate used in the calculations (Blauwens et al. 2016; Sartori et al. 2015). This is the case for the given tram-

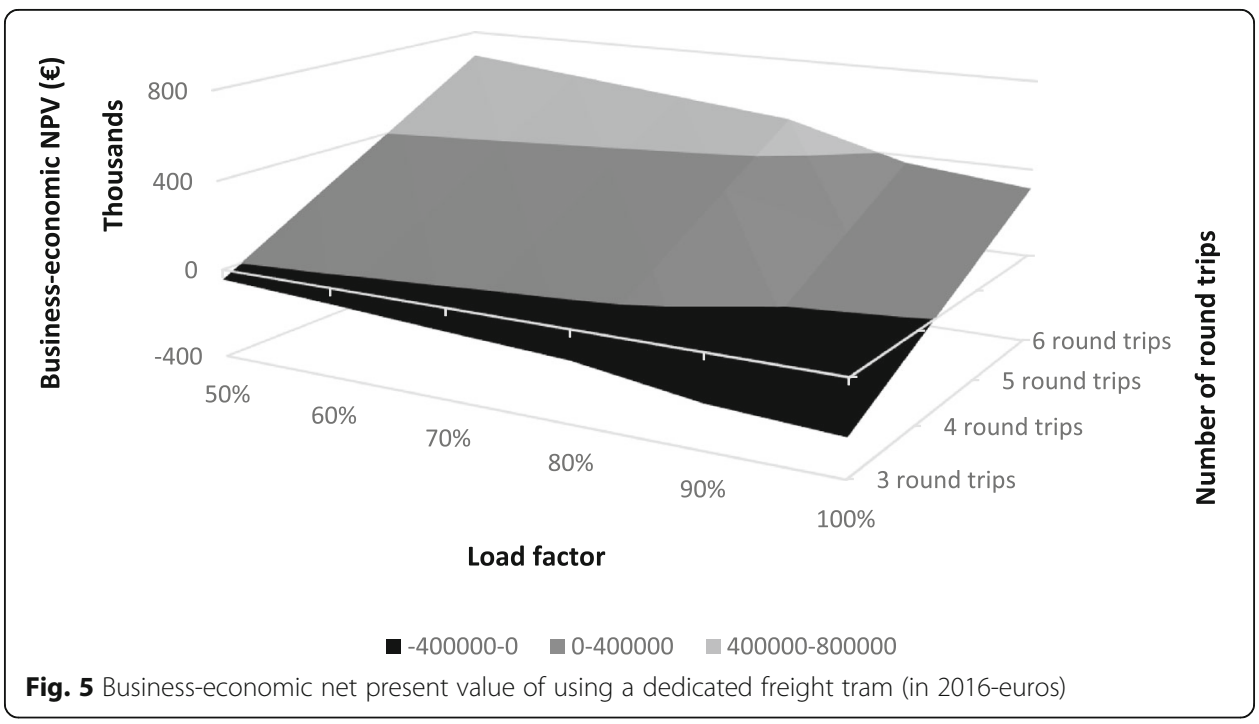




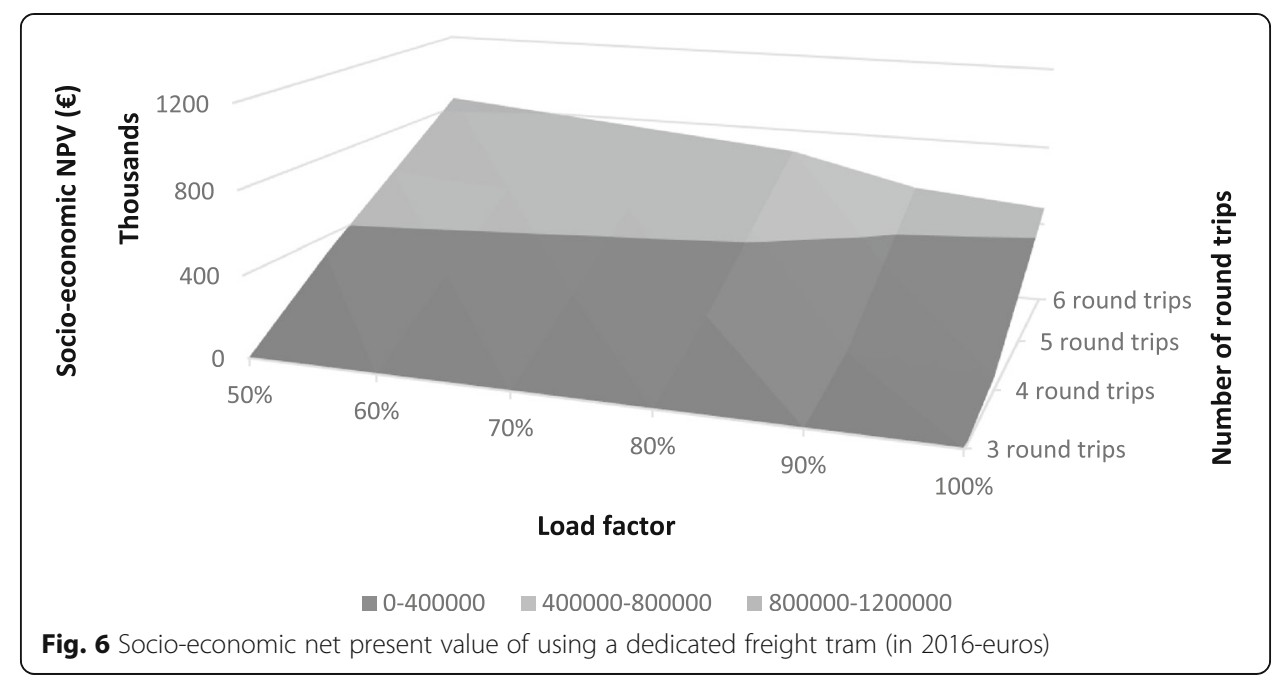

based solution when six round trips are executed at a load factor of maximum $70 \%$. The total volume transported equals then $4200 \mathrm{~kg}^{4}{ }^{4}$ A business-economic net present value (BNPV) of $€ 569,973$ is reached, accompanied by a business-economic internal rate of return of $4.22 \%$. The socio-economic net present value (SNPV) equals $€ 741,854$, complemented by an internal rate of return of $6.38 \%$. The business-economic net present value already becomes positive starting from four round trips, until a load factor of $80 \%$ or lower. The socio-economic net present value is for a load factor of $50 \%$ and $60 \%$ already positive for three round trips, whereas the socio-economic internal rate of return exceeds the social discount rate starting from five round trips, until a load factor of $70 \%$. The business-economic internal rate of return is the strictest in this specific case, only exceeding $4 \%$ for six round trips and a load factor of $50 \%, 60 \%$ or $70 \%$.

After having determined the viability of the tram-based scheme given a number of round trips and a certain load factor, it is now interesting to investigate how this viability changes if some other variables alter. Figure 7 displays the changes in net present value due to a $1 \%$ change of the displayed variables. The variables are ranked according to a decreasing business-economic NPV and are selected following other authors (Boardman et al. 2018; Delaitre and De Barbeyrac 2012; Regué and Bristow 2013; Vadali et al. 2017; Comi et al. 2014). The vertical dotted lines show the $-1 \%$ and $1 \%$ boundary respectively, which is by Sartori et al. (2015) considered to be the start at which variables can be called 'crucial' for the viability of the project. As can be seen in Fig. 7, the operational cost of the current road transport, as well as the marketing revenue are the main variables affecting the net present value in the positive sense. On the contrary, the operational cost of the tram-based project, the speed of the current road transport, the initial capital investment needed and, for the business-economic analysis, the financial discount rate influence the viability in a negative way. Sensitivity analyses are also carried out with respect to the external costs. The results of these analyses are not shown in Fig. 7, since it concerns relative changes compared to another reference point (SNPV instead of BNPV). When the external costs of the truck increase by $1 \%$,

${ }^{4} 4200 \mathrm{~kg}$ is obtained by multiplying six round trips by one tonne net weight and by a $70 \%$ load factor. 


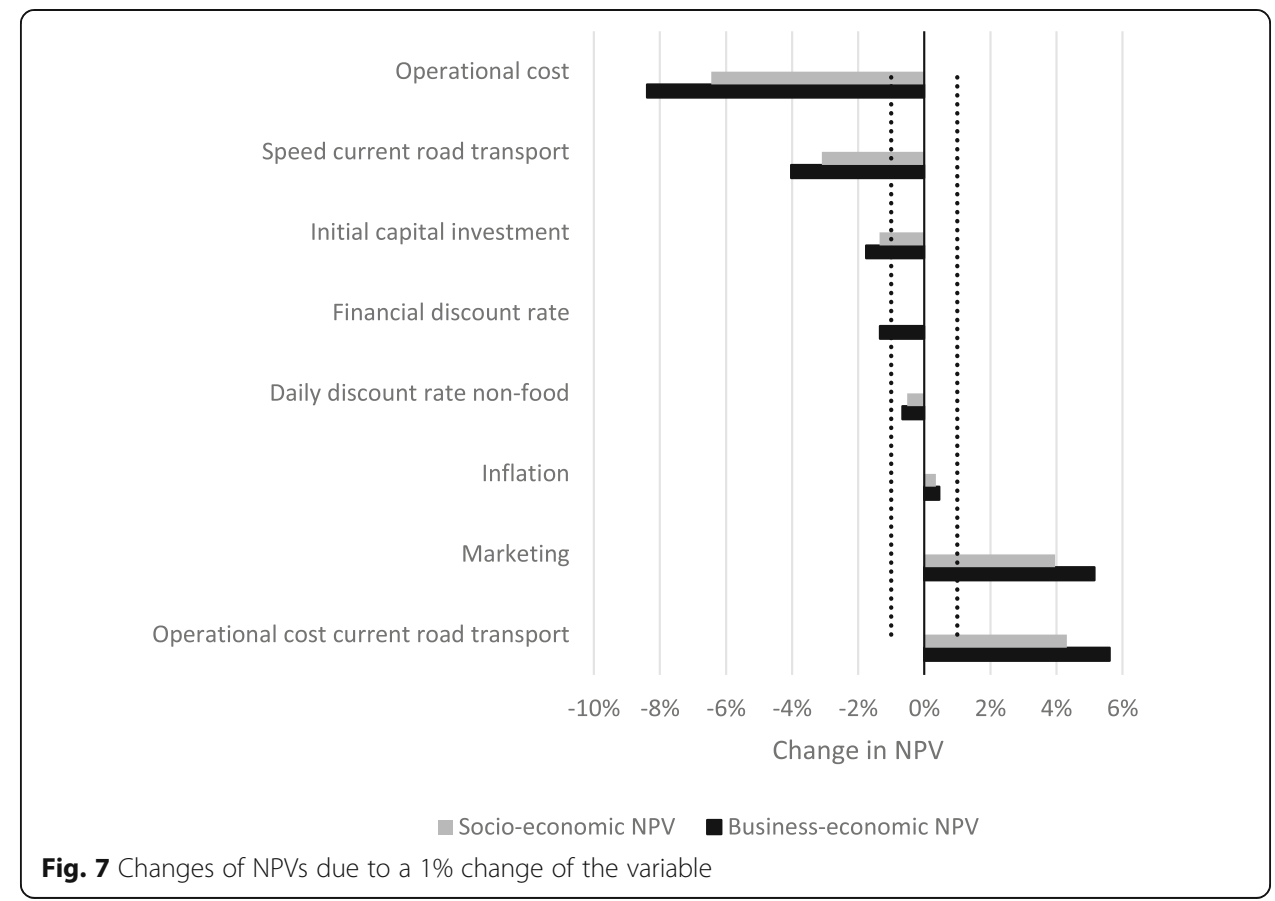

the SNPV increases by $€ 1779$, when the external costs of the tram increase by $1 \%$, the SNPV only decreases by $€ 60$, and when the social discount rate increases by $1 \%$, the SNPV decreases by $€ 7736$. This analysis shows the additional benefits to society that could be gained then shifting from road to tram when the external road costs would be $1 \%$ higher than estimated.

\section{Freight wagon attached to a passenger tram (module 1.2)}

The second cost-benefit illustration comprises the transport of goods in a freight wagon, which is attached to a passenger tram. The same approach was used here as for the calculations in the previous section. Figure 8 displays several combinations of load factors and number of round trips and provides the resulting business-economic net present values. Figure 9 shows the same information regarding the socio-economic net present value. For the business-economic NPV (Fig. 8), the line between the black and grey shaded area represents the boundary where the net present value becomes positive. For the socio-economic NPV (Fig. 9), all shaded areas are positive. It was found that the tram-based solution becomes viable, i.e. has a positive net present value and an internal rate of return larger than the discount rate, starting from six round trips and a load factor of $90 \%$. Hence, the total volume transported here equals $5400 \mathrm{~kg}$. The resulting business-economic net present value equals $€ 59,430$ and is characterised by an internal rate of return of $4.33 \%$. The associated socio-economic net present value is $€ 4,091,629$ and goes with an internal rate of return of $170.88 \%$. These high values for the socio-economic analysis can be explained by the fact that by adding a freight wagon behind a passenger tram, the marginal external costs of the freight wagon are very low, whereas the high external costs of the current road transport are avoided. Hence, the net external benefits are very high for the tram-based solution. 


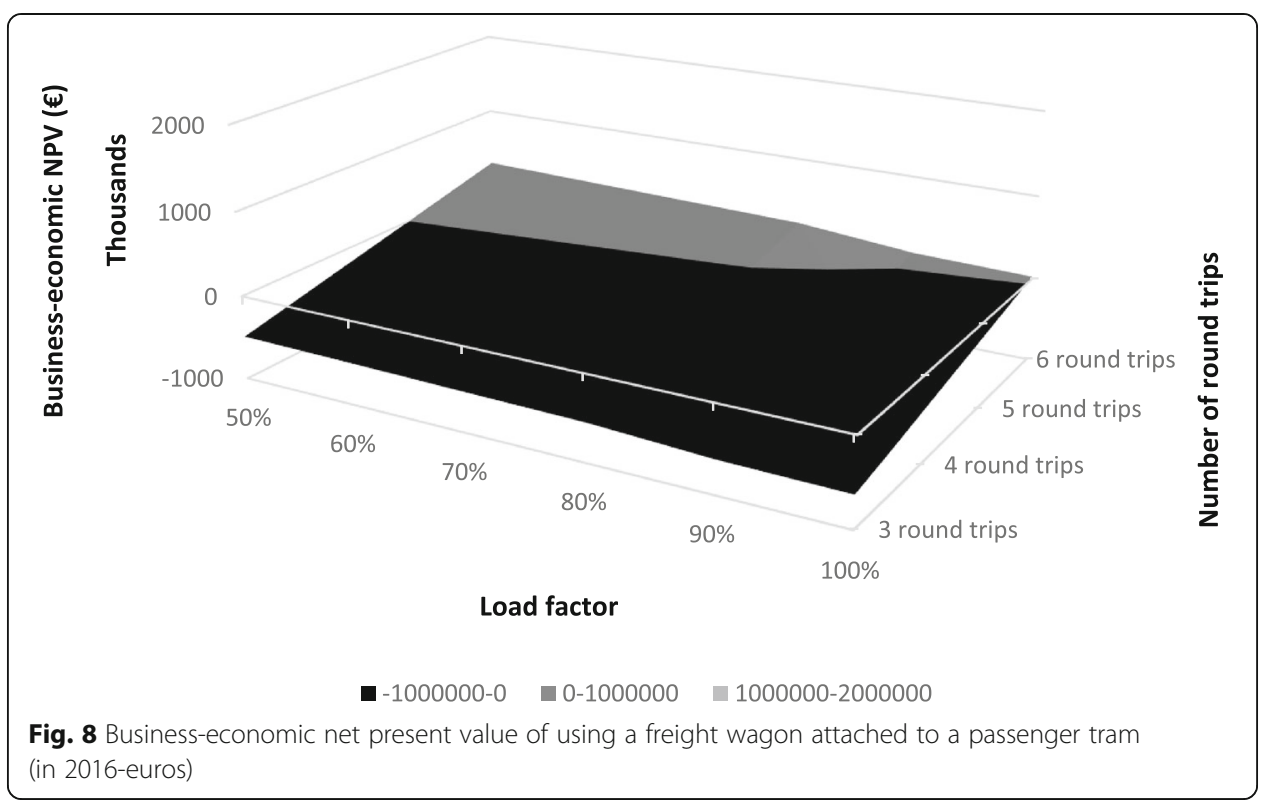

Analogously as in the analysis for a dedicated freight tram, the viability is tested for a number of variables. Figure 10 displays the percentage change of the net present value for a $1 \%$ change of certain variables. The variables are ranked according to a decreasing business-economic NPV. The vertical dotted lines represent the $-1 \%$ change line and the $+1 \%$ change line. Four variables clearly exceed the $1 \%$ boundary with respect to the business-economic NPV. Concerning the socio-economic NPV, no changes of more than $1 \%$ in absolute values are found. The reason for this is the very high value for the socio-economic NPV to which changes are calculated in relative terms. The four crucial variables are: the operational cost of the current road transport (very positive), the operational cost of the tram-based solution, the speed of the current road transport and the daily discount rate of non-food products (all three negative). With respect to the socio-economic analysis, an increase by $1 \%$ of the tram external costs reduces the

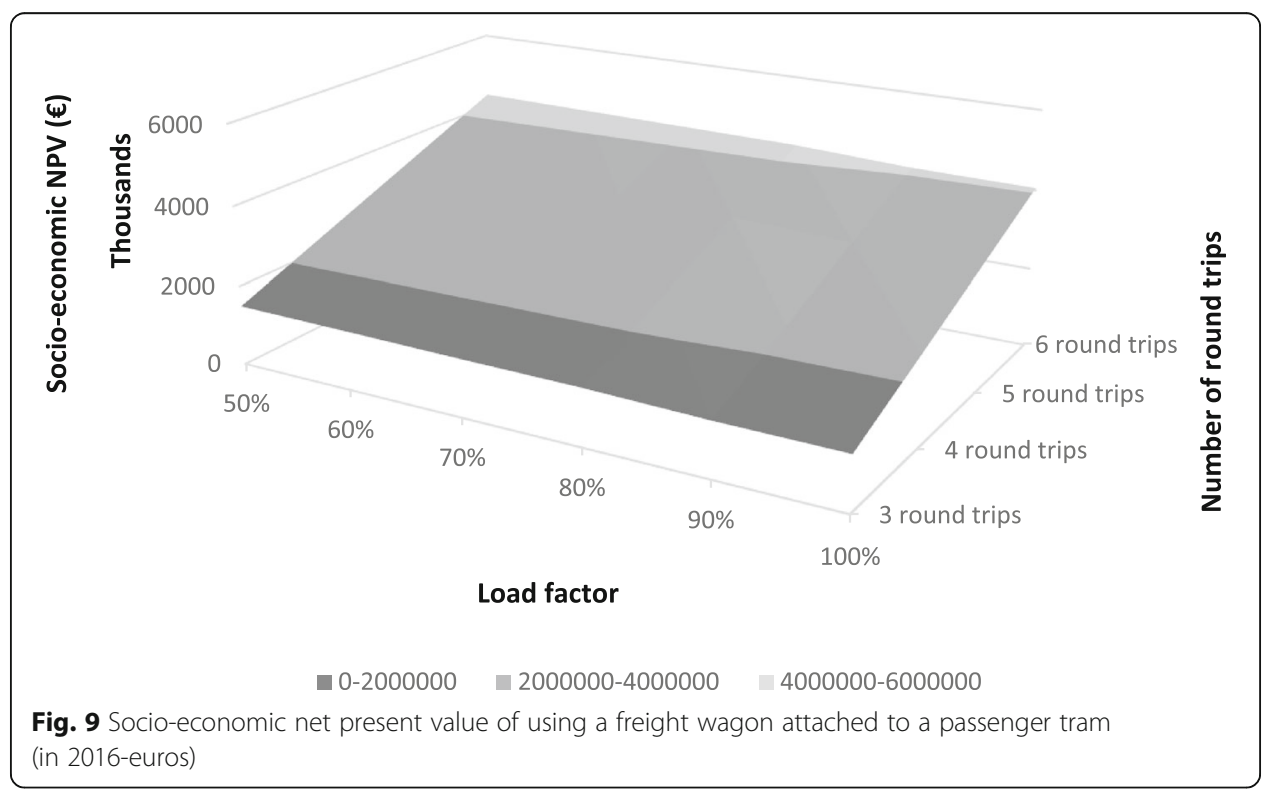




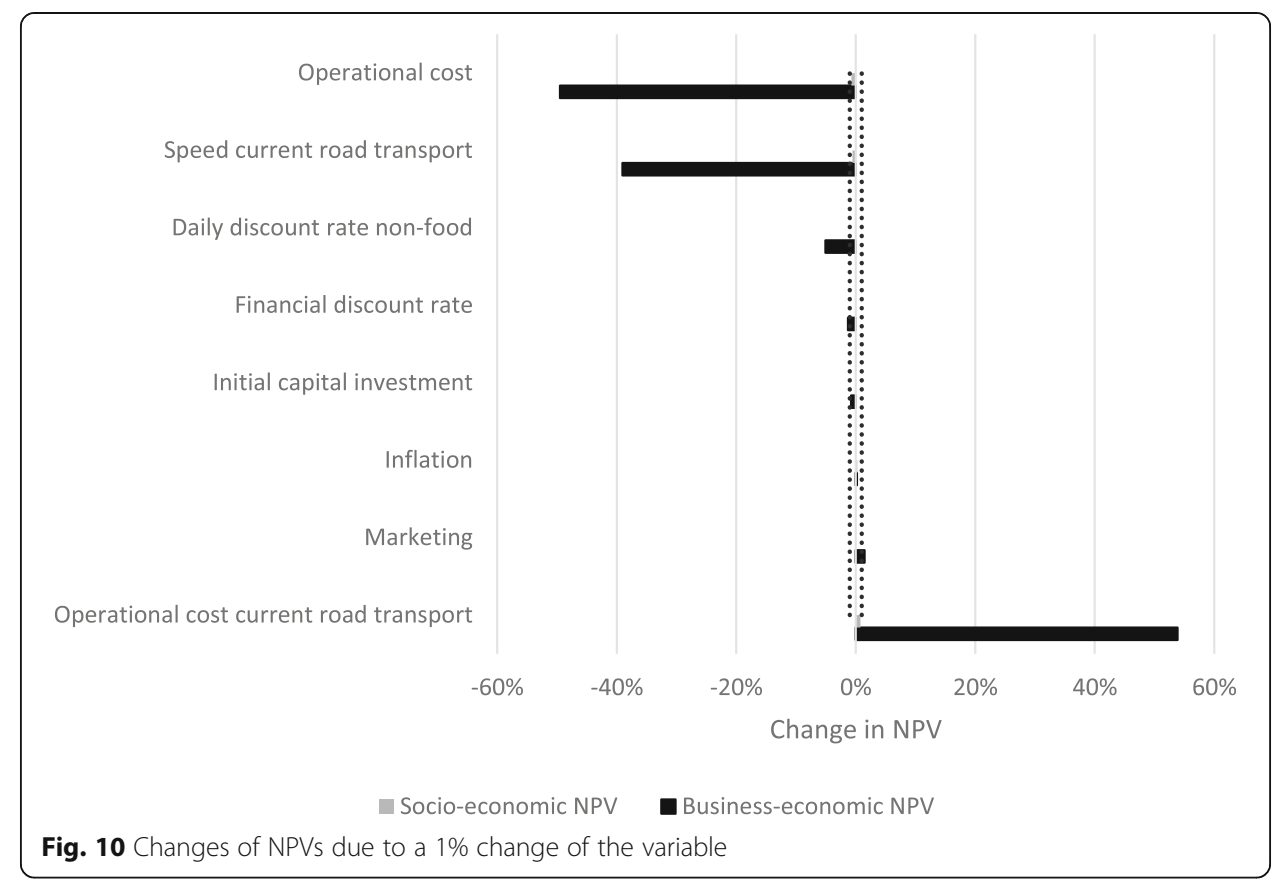

SNPV by $€ 466$, whereas an increase by $1 \%$ of the truck external costs increases the SNPV by $€ 41,365$. An increase of the social discount rate of $1 \%$ leads to an SNPV that is $€ 22,633$ lower. As for the use of a dedicated freight tram, the truck external costs have a large effect on the viability of the tram-based scheme and the effect for a freight wagon is higher than for a dedicated freight tram.

\section{Freight in a passenger tram (module 1.3)}

The third illustration is the transport of a small amount of freight in a passenger tram. It is assumed that a courier transports the cargo in for instance a backpack and delivers it at the customers by using the tram. The courier has to carry the goods and therefore, the maximum weight that can be taken is small. It is assumed that a courier can maximum carry $10 \%$ of its own weight. Assuming an average weight of a courier of $80 \mathrm{~kg}$, a maximum weight of $8 \mathrm{~kg}$ per tram trip is allowed. Hence, the combinations of round trips and load factors of the vans differ in this scenario largely from the two scenarios discussed above. The load factors considered here are $1 \%$ and $2 \%$. From $3 \%$, the business-economic net present value becomes very negative already. Figure 11 displays the business-economic NPV for different combinations of load factors and number of round trips, while Fig. 12 displays the same information concerning the socioeconomic NPV. With respect to the business-economic net present value (Fig. 11), the line between the black and grey shaded area represents the combinations where the net present value becomes positive. Concerning the socio-economic net present value (Fig. 12), all shaded areas are positive. The tipping point in this module is one round trip and a load factor of $2 \%$. The transported volume here is $20 \mathrm{~kg}$. The resulting business-economic net present value is equal to $€ 11,736$, with an internal rate of return of $137.9 \%$. The associated socio-economic net present value is $€ 726,575$, with an internal rate of return of $8345.27 \%$. 


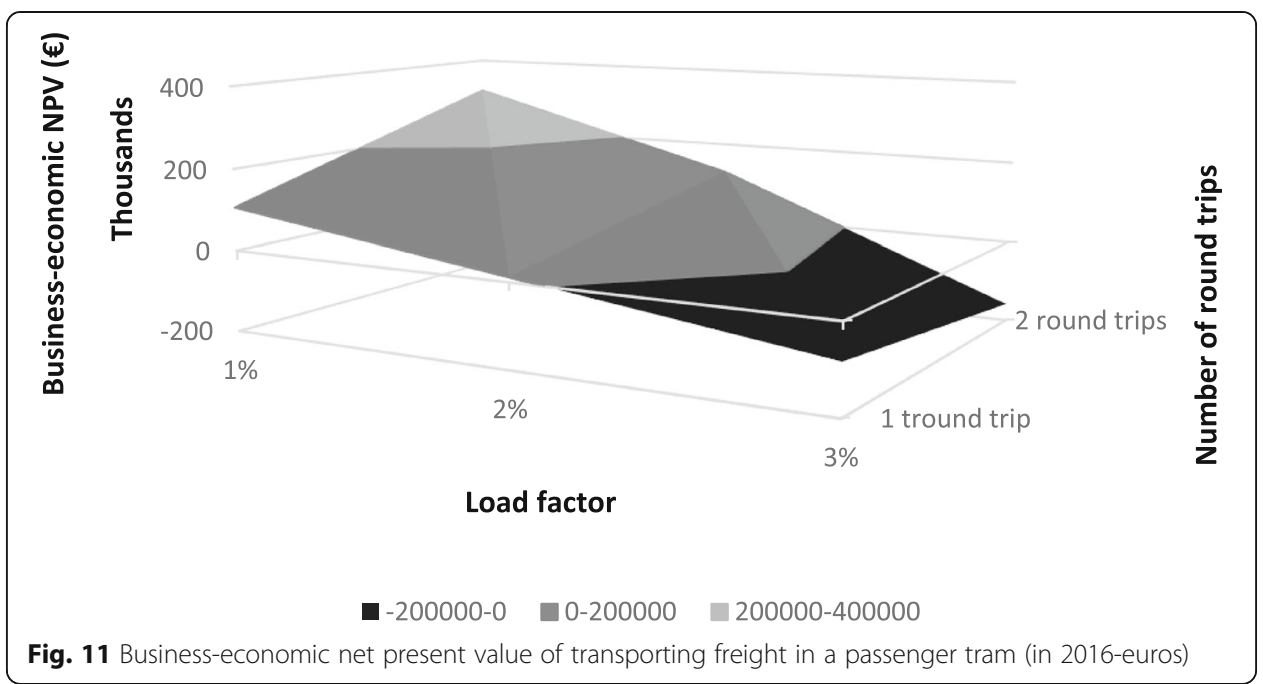

In this module too, sensitivity analyses are carried out with respect to some other variables. The results are shown in Fig. 13. The variables are again ranked according to a decreasing business-economic NPV and the vertical dotted lines represent the $-1 \%$ and $1 \%$ boundaries. The crucial variables with respect to the business-economic NPV are: the operational cost of the current road transport (positive effect), the operational cost of the tram-based solution and the speed of the current road transport (both negative effect). The reason why the variables are not crucial from a socio-economic perspective is again the high NPV in absolute terms. Concerning the effect of the external costs, the change of the SNPV is calculated here as well. No tram external costs are considered present in this module, so the effect of a change of the tram external costs is zero. When increasing the truck external costs by $1 \%$, the SNPV increases by $€ 7149$ and when increasing the social discount rate by $1 \%$, the SNPV decreases by $€ 3934$.

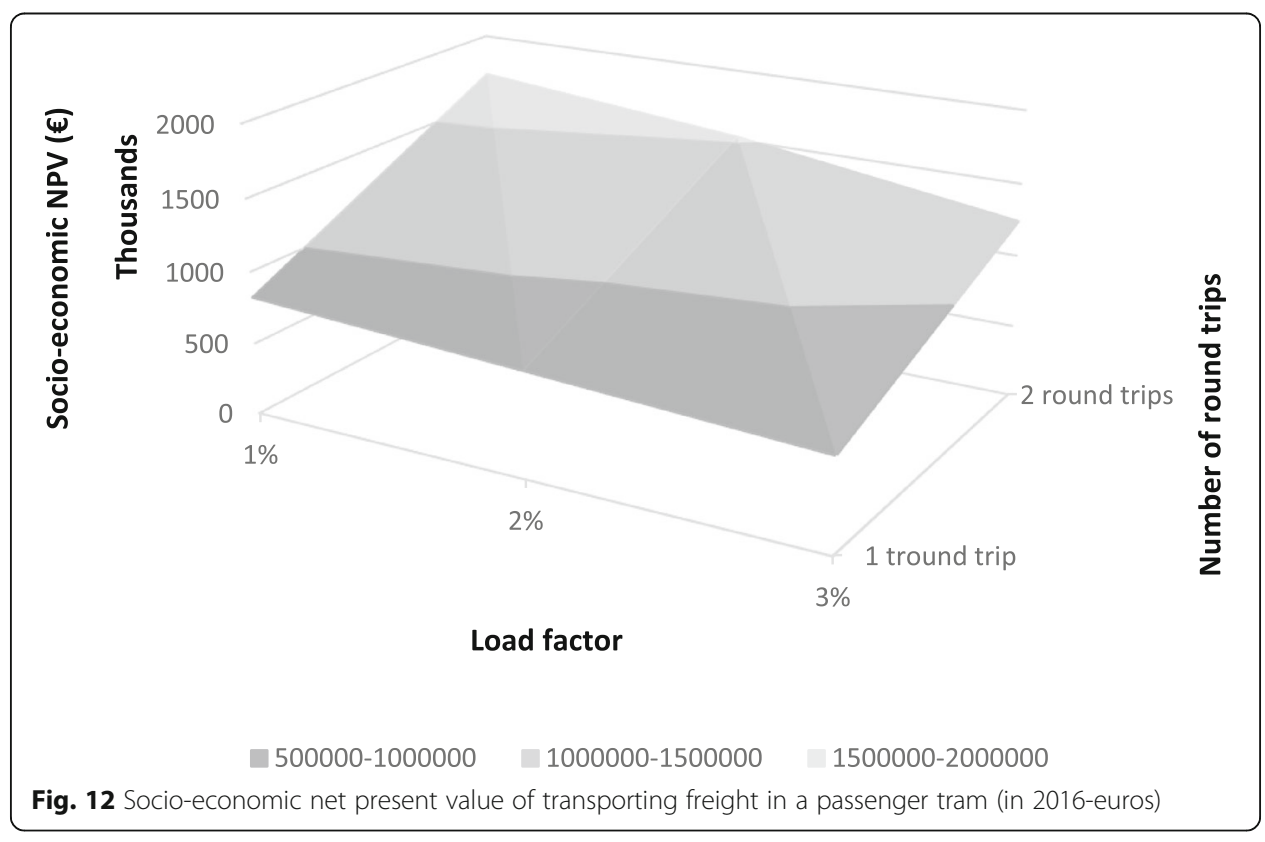




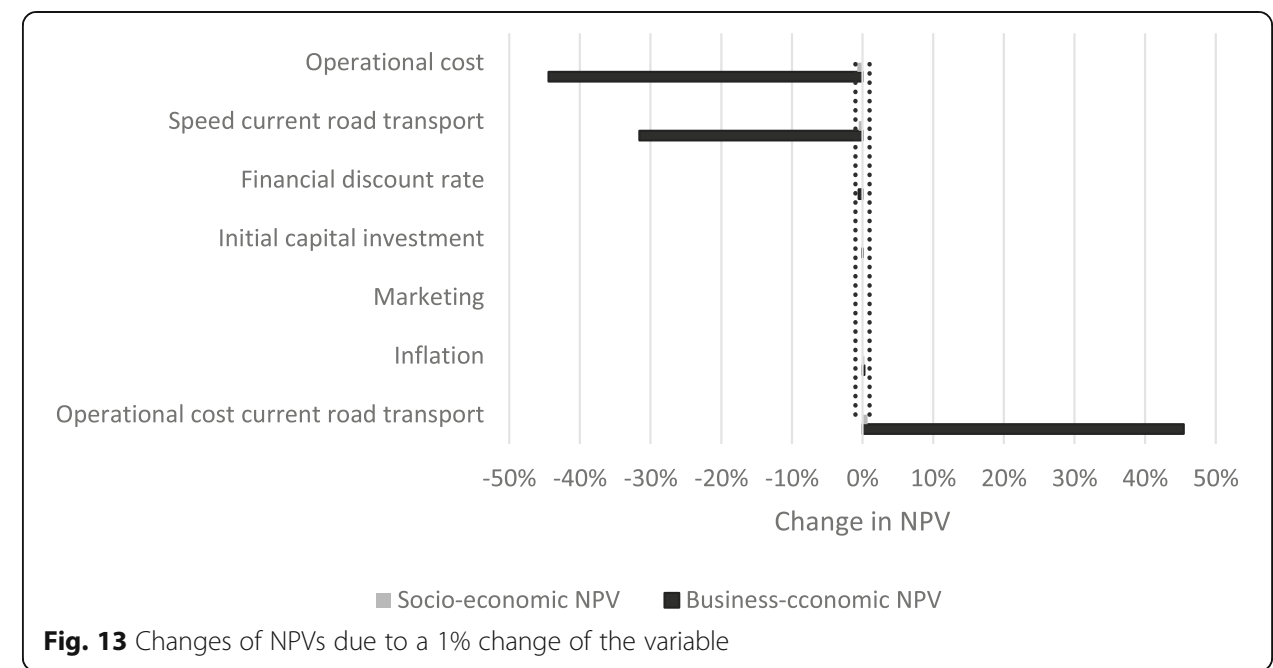

\section{Synopsis}

The main findings of these three illustrations of the viability model differ according to the type of tram transport used. Table 1 shows the output for the three illustrations.

Firstly, the calculations for a dedicated freight tram lead to a positive net present value and an internal rate of return that exceeds the discount rate, both from a business-economic and from a socio-economic perspective, if six round trips are executed and the vans are loaded for maximum $70 \%$. In this case, a total of $4200 \mathrm{~kg}$ of non-food products is transported. Secondly, the transport by a freight wagon behind a passenger tram is viable if six round trips are carried out, given a $90 \%$ load factor of the vans. In total, $5400 \mathrm{~kg}$ of goods are transported here. Thirdly, if a courier transports some goods by using the tram instead of a van, the tram solution is viable if one round trip is done and the van is only loaded for $2 \%$. In this case, the courier transports $20 \mathrm{~kg}$ of goods, spread over three tram trips. It has to be noted here that it will not happen

Table 1 Output of the three illustrations

\begin{tabular}{|c|c|c|c|}
\hline Output & $\begin{array}{l}\text { Module } 1.1 \\
\text { Dedicated freight tram }\end{array}$ & $\begin{array}{l}\text { Module } 1.2 \\
\text { Freight wagon }\end{array}$ & $\begin{array}{l}\text { Module } 1.3 \\
\text { Freight in a } \\
\text { passenger tram }\end{array}$ \\
\hline Viable number of round trips and load factor & $\begin{array}{l}6 \text { round trips and } 50- \\
70 \% \text { load factor }\end{array}$ & $\begin{array}{l}6 \text { round trips and } \\
90 \% \text { load factor }\end{array}$ & $\begin{array}{l}1 \text { round trip, } 2 \% \\
\text { load factor }\end{array}$ \\
\hline Minimum required goods volume & $4200 \mathrm{~kg}$ & $5400 \mathrm{~kg}$ & $20 \mathrm{~kg}$ \\
\hline Business-economic NPV & $€ 2016569,973$ & $€ 201659,430$ & $€ 201611,736$ \\
\hline Business-economic IRR & $4.22 \%$ & $4.33 \%$ & $137.9 \%$ \\
\hline Socio-economic NPV & $€ 2016741,854$ & $€ 20164,091,629$ & $€ 2016726,575$ \\
\hline Socio-economic IRR & $6.38 \%$ & $170.88 \%$ & $8345.27 \%$ \\
\hline Critical business-economic factors & $\begin{array}{l}\text { Initial capital } \\
\text { investment }(-)\end{array}$ & \multicolumn{2}{|c|}{$\begin{array}{l}\text { Initial capital investment \& discount } \\
\text { rate products }(-)\end{array}$} \\
\hline \multicolumn{4}{|l|}{ Marketing (+) } \\
\hline \multicolumn{4}{|l|}{ Operational cost current road transport $(+)$} \\
\hline \multicolumn{4}{|l|}{ Operational cost tram (-) } \\
\hline \multicolumn{4}{|l|}{ Speed current road transport (-) } \\
\hline $\begin{array}{l}\text { Critical socio-economic factor: } \triangle S N P V \text { if exter- } \\
\text { nal truck cost increases by } 1 \%\end{array}$ & $+€ 20161779$ & $+€ 201641,365$ & $+€ 20167149$ \\
\hline
\end{tabular}


very often that a van of $3.5 \mathrm{t}$ is driving a distance of $60 \mathrm{~km}$ to deliver $20 \mathrm{~kg}$ of goods in a city centre. This is still a limitation of the current model that will be elaborated on in further research. Hence, when the current road transport is organised efficiently, with a load factor of $90 \%$, the freight wagon attached to a passenger tram offers some potential. This is not the case for the use of a dedicated freight tram, which is only viable for load factors of the current vans until $70 \%$.

In general, the net present value of the tram-based scheme decreases, from a business-economic and from a socio-economic viewpoint, if the load factor of the vans increases. In other words, the more efficiently the road transport is organised, the less viable shifting to a tram becomes for the three cases examined in this study. On the other hand, the business-economic and socio-economic net present value increase if the number of round trips covered by vans increases. This means that more volume has a positive effect on the viability of the tram-based solution. The combination of the number of round trips and the load factor determines the amount of goods that is transported. For a given amount of goods, a lower load factor leads to more round trips and vice versa. In the illustration presented in this paper, the load factor is altered keeping the number of round trips constant and vice versa. Thus, this leads to a change of the transported volume. This analysis is done in order to know the required volume needed for a successful tram-based solution. This volume is characterised by a certain load factor and a certain number of round trips (as shown for instance in Figs. 5, 6, 8, 9, 11, and 12).

Secondly, the critical factors are derived for the three illustrations. The most critical factors with a positive effect on the viability of the tram-based solution is the operational cost of the current road transport (module 1.1-1.3) and additional marketing revenue (module 1.1). The most critical factors with a negative effect on the viability of the tram scheme are the speed of the current road transport, i.e. the presence of congestion in the urban area (module 1.1-1.3), the initial capital investment (module 1.11.2) and the discount rate of the products, i.e. the depreciation (module 1.3). When the transported goods are higher value products, or fast moving consumer goods instead of non-food retail products, the discount rate of the products will even play a higher role. From a socio-economic perspective, the truck external costs affect the net present value the most and here again, the effect is the highest for the use of a freight wagon attached to a passenger tram. Hence, this type of tram transport offers the most benefit opportunities for society.

Some other variables are still very interesting to check upon their impact on the viability of the tram-based scheme, but cannot be altered by increasing them by $1 \%$ as was done before. Figure 14 provides an overview of the change in the business-economic (BNPV) and socio-economic (SNPV) net present value for each variable that is altered for the three types of tram transport considered in this paper. The variables are ranked according to a decreasing BNPV. The variables with the highest positive impact in favour of the tram-based scheme, are twofold. Firstly, the shift of the transport to peakhours instead of off-peak-hours results in an increase of the business-economic NPV and an increase of the socio-economic NPV for all three types of tram transport. It has to be added here that using a tram for freight purposes during peak hours might not be feasible from an organisational perspective, since the public tram network may be saturated. Secondly, if road pricing would be extended to trucks of less than or equal to 3.5 


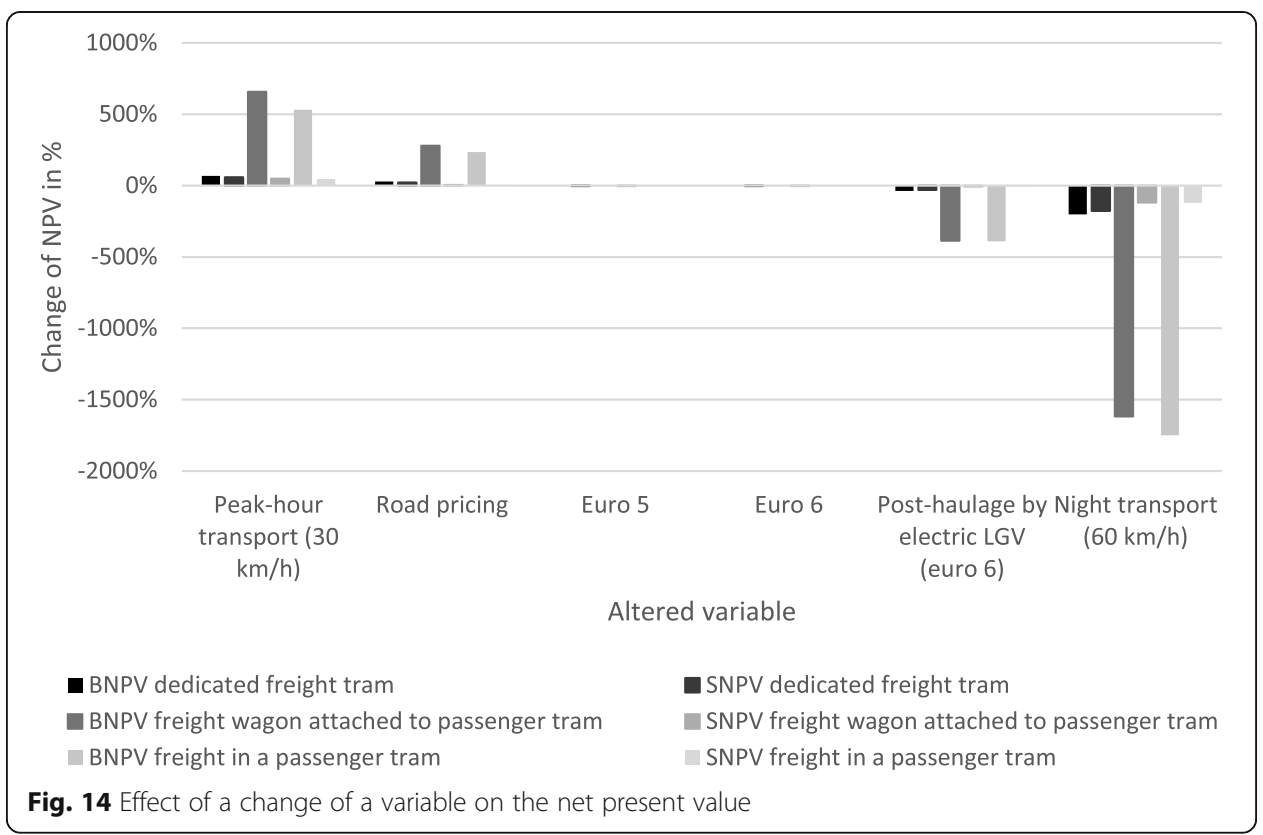

$\mathrm{t}$ gross weight, this would also have a positive effect on the viability of a shift to tram transport. At the right side of Fig. 14, it can be seen that adding road post-haulage to the tram solution, as well as moving the transport from off-peak hours to the night, results in a business-economic and socio-economic loss for all types of tram transport. The change to euro 5 or euro 6 vans does not lead to large changes in the NPV.

\section{Conclusion}

This paper investigates how urban freight transport by tram can be viable from a business-economic and from a socio-economic perspective. A viability model is developed and illustrated by three types of tram transport for some round trips in the city of Antwerp: a dedicated freight tram, a freight wagon attached to a passenger tram, or a courier transporting a small amount of freight in a passenger tram.

Some variables are more crucial in the determination of the viability of the tram solution than others. For all three tram types, it was found that the operational cost of the current road transport has a positive effect on the viability of transporting goods by tram. From a socio-economic perspective, the effect of the truck external costs is the highest. The most benefits can potentially be obtained when attaching a freight wagon to a passenger tram. On the other hand, for all three types it was shown that the operational cost of the tram-scheme and the speed of the current road transport negatively affect the viability of using a tram for urban freight distribution. Moreover, it would be beneficial for all three types to conduct the tram transport during peak-hours. However, some organisational limitations due to the saturation of the public tram network have to be taken into account here. If the tram network is saturated by passenger traffic, it is assumed that the price that has to be paid to obtain a slot for freight transport is so high, that the tram-based freight solution cannot be successful. Other organisational limitations, such as the fact that a certain tram stop cannot be used for freight activities, can be added to the developed model by assigning a cost to them. If road pricing would be extended to all types of vans, this would be in favour of the tram. On 
the contrary, if road post-haulage is needed to reach the customer, or if the transport takes place during the night, shifting from road to tram is disadvantageous. An important remark is the effect of the product type on the costs and benefits for all three tram types. In the illustration in this paper, non-food retail products are considered. When the analysis is extended to for instance refrigerated or frozen food, additional costs such as cooling and additional transport equipment have to be added.

The results of this paper are most interesting for a number of stakeholders. Firstly, authorities can use the insights as part of their sustainable urban logistics plans (SULPs). Moreover, the development of the social cost-benefit framework provides a tool for policy makers through which they can determine which urban rail freight projects are beneficial to society. Authorities can decide on compensating private players for their potential costs when using the tram-based scheme when this would be beneficial to society as a whole. Secondly, tram operators can be assisted in understanding how they can extend the scope of their activities. Next to passenger transport, they can also consider freight activities. Idle time of rolling stock or drivers could for instance be used to supply retailers in the urban area. Thirdly, suppliers and retailers can learn under which conditions shifting from road to rail can become interesting from a business-economic viewpoint. Although the analysis in this research is performed from the viewpoint of the authorities, suppliers and retailers can derive the private costs that are borne by them when shifting from road to tram, as well as the private benefits they gain. The private costs are for these players equal to the price they would pay to the tram operator for using the tram-based solution. The benefits consist of the current transport costs that they do not have to pay for anymore. Moreover, some time savings can be gained as well as a potential reduction of the in-store storage space and potential lower shop personnel costs.

Some interesting avenues for further research exist. Firstly, the business-economic analysis will be extended by including the calculation of the return on capital and the return on investment if the investor is a private actor. Secondly, the evaluation measures will be extended by the calculation of the benefit-cost ratio in order to make the decision framework more robust. Thirdly, additional variables will be tested on their effect on the NPV. Examples are the presence of more customers in the urban area and other types of vehicles. Ultimately, the knowledge gathered here on costs and benefits, and on crucial variables affecting the viability of using a tram for urban freight can be used as input for mixed integer programming models.

Abbreviations

BNPV: Business-economic Net Present Value; IRR: Internal Rate of Return; LGV: Light Goods Vehicle; NPV: Net Present Value; SNPV: Socio-economic Net Present Value; SULP: Sustainable Urban Logistics Plan

Acknowledgements

Not applicable.

Authors' contributions

$\mathrm{KDL}$ collected the data, set up the viability model, interpreted the results and was a major contributor in writing the manuscript. HM, CS, TV and EVDV took part in intermediary discussions on the data, model and results and provided substantive input in improving the conceptual design and paper structure. All authors read and approved the final manuscript. 
Funding

No external funding.

\section{Availability of data and materials}

All data generated or analysed during this study are available from the corresponding author on reasonable request.

\section{Competing interests}

The authors declare that they have no competing interests.

Received: 17 July 2019 Accepted: 26 November 2019

Published online: 05 December 2019

\section{References}

Alejandro Cardenete M, López-Cabaco R (2018) How modes of transport perform differently in the economy of Andalusia. Transp Policy 66:9-16. https://doi.org/10.1016/j.tranpol.2018.02.015

Annys A, De Buck Fernand, De Meyer P, De Volder Daniël, Kinds Luc, Vancraeynest R (1994) Het Openbaar Vervoer Te Brugge - Deel 1: De Stadstram

Arencibia Al, Feo-Valero M, García-Menéndez L, Román C (2015) Modelling mode choice for freight transport using advanced choice experiments. Transp Res A Policy Pract 75(May):252-267. https://doi.org/10.1016/j.tra.2015.03.027

Aronietis R, Sys C, Vanelslander T (2016) Maritime transport company strategies: how to be sustainable in the future. In: Finger M (ed) The Routledge companion to network industries. Routledge, Abingdon, pp 325-343

Arvidsson N (2010) New perspectives on sustainable urban freight distribution: a potential zero emission concept using electric vehicles on trams. In: Lisbon, Portugal

Arvidsson N, Browne M (2013) A review of the success and failure of tram systems to carry urban freight: the implications for a low emission intermodal solution using electric vehicles on trams. Eur Trans 54(5):1-18

Ayadi A (2014) Vers une organisation globale durable de l'approvisionnement des ménages: Bilans économiques et environnementaux de différentes chaînes de distribution classiques et émergentes depuis l'entrepôt du fournisseur jusau'au domicile du ménage. Doctoral thesis, Université Lumière Lyon II, Lyon

Behiri W, Belmokhtar-Berraf S, Chu C (2018) Urban freight transport using passenger rail network: scientific issues and quantitative analysis. Transport Res E Log 115(July):227-245. https://doi.org/10.1016/j.tre.2018.05.002

Bektas T, Crainic TG, Van Woensel T (2016) From managing urban freight to smart city logistics networks. In: Gakis K, Pardalos P (eds) Network design and optimization for smart cities, vol 8, pp 143-188. Series on computers and operations research, volume 8. World Scientific. https://doi.org/10.1142/9789813200012_0007

Blauwens G, De Baere P, Van de Voorde E (2016) Transport economics, 6th edn. De Boeck, Antwerp

Boardman AE, Greenberg DH, Vining AR, Weimer DL (2018) Cost-benefit analysis: concepts and practice, 5th edn. Cambridge University Press, Cambridge, UK

Campos J, Hernández A (2010) Cost-benefit analysis and demand uncertainty: evaluating the high-speed rail network in Spain. University of Las Palmas, Mimeo

Cavallaro F, Giaretta F, Nocera S (2018) The potential of road pricing schemes to reduce carbon emissions. Transport policy, efficient, safe and intelligent transport. Selected papers from the XII Conference on Transport Engineering, 67 (September), pp 85-92. https://doi.org/10.1016/j.tranpol.2017.03.006

Chang T-H, Tseng J-S, Hsieh T-H, Hsu Y-T, Ying-Chih L (2018) Green transportation implementation through distance-based road pricing. Transp Res A Policy Pract 111:53-64. https://doi.org/10.1016/j.tra.2018.02.015

City of Antwerp (2018) Demografie. Stad in Cijfers: Databank. https://stadincijfers.antwerpen.be/databank/

Cleophas C, Cottrill C, Ehmke JF, Tierney K (2018) Collaborative urban transportation: recent advances in theory and practice. Eur J Oper Res. https://doi.org/10.1016/j.ejor.2018.04.037

Cochrane K, Saxe S, Roorda MJ, Shalaby A (2017) Moving freight on public transit: best practices, challenges, and opportunities. Int J Sustain Transp 11(2):120-132. https://doi.org/10.1080/15568318.2016.1197349

Comi A, De Langhe K, Doomernik J, Filippi F, Gevaers R, Gonzalez-Feliu J, Goossenaerts M et al (2014) Expert meeting: tramways, railways and cities - tackling the role of rail in urban freight distribution. Antwerp

Cruz C, Montenon A (2016) Implementation and impacts of low emission zones on freight activities in Europe: local schemes versus national schemes. Transportation Research Procedia, tenth international conference on city logistics 17-19 June 2015, Tenerife, Spain, 12 (January), pp 544-556. https://doi.org/10.1016/j.trpro.2016.02.010

Delaître, Loic, and C.édric De Barbeyrac (2012) Improving an urban distribution centre, the French case of Samada Monoprix. Procedia Soc Behav Sci 39:753-769. https://doi.org/10.1016/j.sbspro.2012.03.145

Diziain D, Taniquchi E, Dablanc L (2014) Urban logistics by rail and waterways in France and Japan. Procedia social and behavioral sciences, eighth international conference on city logistics 17-19 June 2013, Bali, Indonesia, 125 (March),pp 159-170. https://doi.org/10.1016/j.sbspro.2014.01.1464

European Commission (2018) What Do We Want to Achieve? Sustainable Transport. https://ec.europa.eu/transport/themes/ sustainable en

Fredriks.de. (2018) Strassenbahnen in Hamburg: Strassenbahn Und Post. Strassenbahnen in Hamburg. https://fredriks.de/hvv1/ strabpostverkehr.php

Gonzalez-Feliu J (2016) Viability and potential demand capitation of urban freight tramways via demand-supply Modelling and cost benefit analysis. In: Proceedings of the 6th international conference in informations systems, logistics and supply chain. Bordeaux, France: Kedge Business School, Bordeaux

Heesvelde V, Paul RT, De Troy M, De Meyer P (2018) Sporen in de Modder - Trams En Buurtspoorwegen Tijdens de Eerste Wereldoorlog. Snoeck, Gent

Kidokoro Y (2004) Cost-benefit analysis for transport networks: theory and application. J Transport Econ Policy 38(2):275-307

Kikuta J, Ito T, Tomiyama I, Yamamoto S, Yamada T (2012) New subway-integrated city logistics system. Procedia Soc Behav Sci 39:476-489. https://doi.org/10.1016/j.sbspro.2012.03.123 
Korzhenevych A, Dehnen N, Bröcker J, Holtkamp M, Meier H, Gibson G, Varma A, Cox V (2014) Update of the handbook on external costs of transport. Final Report for the European Commission: DG Move. DIW, CAU, Ricardo-AEA

Letnik T, Marksel M, Luppino G, Bardi A, Božičnik S (2018) Review of policies and measures for sustainable and energy efficient urban transport. Energy 163:245-257. https://doi.org/10.1016/j.energy.2018.08.096

Macário R, Rodrigues M, Gama A, Timms P, Lama C, Amaral M, Schoemaker J, Tromp N, Quinn Derek, Abranches G. 2011. Handbook on urban logistics - Turblog_ww: transferability of urban logistics concepts and practices from a worldwide perspective

Maes J (2017) The potential of cargo bicycle transport as a sustainable solution for urban logistics. Doctoral thesis, University of Antwerp, Antwerp

Maes J, Sys C, Vanelslander T (2011) Low emission zones in Europe: their impact on sustainability and logistics. In: Proceedings of the METRANS National Urban Freight Conferences. Long Beach, pp 1-23

Marinov M, Giubilei F, Gerhardt M, Özkan T, Stergiou E, Papadopol M, Cabecinha L (2013) Urban freight movement by rail. J Transport Lit 7(3):87-116. https://doi.org/10.1590/S2238-10312013000300005

Mirhedayatian SM, Yan S (2018) A framework to evaluate policy options for supporting electric vehicles in urban freight transport. Transp Res Part D: Transp Environ 58(January):22-38. https://doi.org/10.1016/j.trd.2017.11.007

Motraghi A, Marinov MV (2012) Analysis of urban freight by rail using event based simulation. Simul Model Pract Theory 25(June):73-89. https://doi.org/10.1016/j.simpat.2012.02.009

Ozturk O, Patrick J (2018) An optimization model for freight transport using urban rail transit. Eur J Oper Res 267(3):11101121. https://doi.org/10.1016/j.ejor.2017.12.010

Pimentel C, Alvelos F (2018) Integrated urban freight logistics combining passenger and freight flows - mathematical model proposal. Transportation Research Procedia, EURO Mini Conference on 'Advances in Freight Transportation and Logistics', 30 (January):80-89. https://doi.org/10.1016/j.trpro.2018.09.010

Posttip.de (2007) Citipost-Briefkästen in Der Bremer Tram. News. April 12. http://www.posttip.de/briefe/news/citipostbriefkaesten-in-der-bremer-tram/

Regué R, Bristow AL (2013) Appraising freight tram schemes: a case study of Barcelona. Eur J Transp Infrastruct Res 13(1):5678. https://doi.org/10.18757/ejtir.2013.13.1.2988

Sartori D, Catalano G, Genco M, Pancotti C, Sirtori E, Vignetti S, Del Bo C (2015) Guide to cost-benefit analysis of investment projects. Economic appraisal tool for cohesion policy 2014-2020. Italy: European Commission

Shen J, Qiu F, Li W, Feng P (2015) A new urban logistics transport system based on a public transit service. In: Proceedings of the international conference of transportation professionals (CICTP 2015), pp 650-661. https://doi.org/10.1061/ 9780784479292.060

Slim naar Antwerpen (2019) Lage-Emissiezone. https:/www.Slimnaarantwerpen.be/nl/lez

TomTom (2017) Antwerp. TomTom Traffic Index. https://www.tomtom.com/en_gb/trafficindex/city/antwerp

Trojanowski J, Iwan S (2014) Analysis of Szczecin waterways in terms of their use to handle freight transport in urban areas. Procedia Soc Behav Sci Green Cities - Green Logistics for Greener Cities, Szczecin, 19-21 May 2014, 151 (October):333341. https://doi.org/10.1016/j.sbspro.2014.10.031

United Nations (2018) Promoting environmentally sustainable transport (EST). Implementation Methodologies. https:// sustainabledevelopment.un.org/partnership/?p=365

Vadali S, James Kruse C, Kuhn K, Goodchild A (2017) Guide for conducting benefit-cost analyses of multimodal, multijurisdictional freight corridor investments. 38. National Cooperative Freight Research Program. Transportation Research Board, Washington, DC

VGF (2018) Pilotprojekt. Frankfurts Erste Logistiktram Geht Auf Die Schiene September 17. https://www.vgf-ffm.de/de/ aktuellpresse/news/einzelansicht/news/pilotprojekt/

Viapass (2018) Kilometer charge: tariffs and toll maps as from January 1 2018. http://www.viapass.be/en/downloads/

Vigren A, Ljungberg A (2018) Public transport authorities' use of cost-benefit analysis in practice. Res Transport Econ. https:// doi.org/10.1016/j.retrec.2018.06.001

\section{Publisher's Note}

Springer Nature remains neutral with regard to jurisdictional claims in published maps and institutional affiliations.

\section{Submit your manuscript to a SpringerOpen ${ }^{\circ}$ journal and benefit from:}

- Convenient online submission

Rigorous peer review

- Open access: articles freely available online

- High visibility within the field

- Retaining the copyright to your article

Submit your next manuscript at $\boldsymbol{\nabla}$ springeropen.com 